\title{
Measuring the Value of Pharmaceuticals in the US Health System
}

\author{
Surrey M. Walton ${ }^{1} \cdot$ Anirban Basu $^{2} \cdot$ John Mullahy $^{3} \cdot$ Samuel Hong ${ }^{4} \cdot$ \\ Glen T. Schumock ${ }^{5}$
}

Published online: 27 October 2016

(c) Springer International Publishing Switzerland 2016

Several recent innovations in prescription drug treatments in oncology, hepatitis C, and lipid therapy, among others, have demonstrably improved health for particular patient populations [1-3]. However, many of these new therapies have also come at a very high price. Demographic trends are certain to increase the future demand for care, making growth in overall healthcare spending in the USA a longrunning concern and the explosion in pharmaceutical expenditures has been a hot topic recently in the medical and lay press $[4,5]$. Concerns about drug pricing and spending have prompted discussions about the value of new drugs, and whether pricing should be tied to value [6]. In this editorial, we explore the concept of value-based pricing. We begin with a discussion of value as it applies to the pricing of pharmaceuticals, and include a discussion of current efforts in creating value frameworks, as well as the inherent complexities in assessing value. In addition, value measurement of pharmaceuticals in the context of willingness-to-pay (WTP) frameworks is considered, followed

Surrey M. Walton

walton@uic.edu

1 Department of Pharmacy Systems Outcomes and Policy, College of Pharmacy, University of Illinois, 833 S. Wood Street (M/C 871) rm 287, Chicago, IL 60612, USA

2 Department of Pharmacy, School of Pharmacy, University of Washington, Seattle, USA

3 Department of Population Health Sciences, University of Wisconsin, Madison, USA

4 College of Pharmacy, University of Illinois, Chicago, USA

5 Department of Pharmacy Systems Outcomes and Policy, College of Pharmacy, University of Illinois, Chicago, IL, USA by some suggestions for how best to proceed in terms of improving relevant evidence related to value along with a cautionary description of the inherent risks involved in rigid applications of value and/or WTP frameworks to set the prices of new treatments.

The concept of value is salient in the pharmaceutical market for several reasons. First, drug manufacturers are granted monopoly power through patents and by the US Food and Drug Administration over newly approved innovations, and with restrictions, are allowed, to market those products, set prices, and negotiate with payers for discounts and rebates. There are strong incentives and corresponding efforts by both the industry and payers to consider all the available evidence when negotiating prices, including estimates pertinent to value. Further, the process of approval by payers, competition between payers and between pharmaceutical manufacturing firms, and the value of reputation in the market all serve as checks that limit low-value medications from garnering excessive profits. However, payers are often forced to make coverage and payment decisions for new treatments for groups of patients based on limited information as well as in circumstances where few alternative treatments exist. Additionally, different prices are negotiated between drug companies and various sets of payers. Further, prices of one product may be determined in conjunction with negotiations regarding prices and quantities of related products covered by payers such that the resulting prices of several products may not reflect their underlying value. These prices in turn have direct effects on the overall costs of a health plan reflected through insurance premiums both in the private and the public managed care markets. Meanwhile, patients face limited information and limited choices in making decisions about their healthcare options, 
which in turn may have substantial financial and healthrelated consequences. In fact, the decision to use a drug is often made by a physician who may not even know the underlying cost, and in some cases may face incentives to prescribe more expensive agents [7]. Further, there is the potential that patients are required to pay for high-cost treatments that are not covered or under-covered by their insurance, and that in a social context should be fully covered [8]. On top of that, payments to drug companies for successful products act as a financial incentive for innovations, and drug coverage for many in USA is mixed in with progressive taxes and related societal goals for income redistribution (e.g., Medicaid coverage for lowincome patients). The end result is a potentially dysfunctional market where prices paid by buyers, patients, and their insurers may not always reflect the true value of the treatment, where certain subsets of the population may not receive access to valuable medications, and where companies may be over or under-rewarded for creating new products.

Consequently, there can be important roles for stakeholders beyond payers and pharmaceutical companies to provide measures of the value of pharmaceutical treatments as a mechanism for steering treatment decisions and related payment policies towards high-value treatments. Recently, there have been several attempts by provider organizations and other entities at creating value frameworks for drug treatments. Examples of organizations with such initiatives include the American Society of Clinical Oncology, the American College of Cardiology and American Heart Association, the Memorial Sloan Kettering Cancer Center, and the National Comprehensive Cancer Network as well as the Institute for Clinical and Economic Review [6, 9-11]. These frameworks vary across several dimensions, including the disease(s) targeted (though most are focused on cancer) and the underlying perspective and overall purpose, which range from helping inform clinicians and patients to setting drug prices. A recent commentary by Neumann and Cohen provides further detail as well as a useful discussion of their limitations [12]. All consider health and at least some aspect of costs, but at best with limited health measures and often with ad-hoc combinations of metrics. A fundamental limitation of all the frameworks is the absence of any well-defined theoretical basis for how to measure value, which inherently requires estimating the rate at which stakeholders are willing to forgo one attribute of health with another, or any related empirical analyses regarding how payers, physicians, or patients would or should make decisions based on the available metrics.

There are several substantial hurdles in getting to a more theoretically and practically sound system for assessing value. First, there is typically substantial heterogeneity in patient responses to drugs, much of which requires broad use of the medication in various patient groups before it can be fully characterized. For example, Basu et al. illustrate how coverage policy based solely on initial average cost effectiveness of a treatment can have a negative impact on patient welfare based on empirical findings for anti-psychotic drugs [13]. Further, there are differences in patient preferences for specific health outcomes that can result in treatments with similar summary scores being perceived as having different value to patients. For example, shapes of the underlying survival curves for different cancer treatments can have the same median survival but because of their performance early on or because of a potential for a long tail be more or less preferable to particular patients. A 2012 study by Lakdawalla et al. found a large consensus, though not universal, for the value of 'hope' in terms of longer tails in survival curves [14, 15]. Overall, greater efforts should be made in obtaining patient's perspectives regarding the value of treatments that may or may not relate to existing summary measures of health and/or medical standards for clinical decision making [16].

Another complicating factor in value assessment is that there are dimensions of value that are beyond the gains/loss in health to an individual patient and thus may not be valued by the individual. These include externalities in health both in the sense that impacting the health of one person often impacts others' lives, as well as in how treating or preventing a disease in one patient can improve the expected health of many. In addition, current treatments act as building blocks for future innovations and may have scientific spillovers, and often the outcomes for specific treatments improve over time with learning by clinicians. Treatments, when successful, may also serve as mechanisms for reducing financial risk for patients.

Even when ignoring some of these broader potential impacts of new treatments, a fundamental issue in assessing the value of a treatment is how to measure and compare health outcomes and costs. Typically, treatment-related health outcomes are measured in clinical units. Efforts have been made to summarize long-run health gains with metrics such as quality-adjusted life-years, but these have their own host of measurement issues [17]. In assessing the dollar value of benefits related to treatments, a central concept is WTP. The general mechanism we have for examining WTP is through discrete choice experiments and/or contingent valuation surveys where there is plenty of evidence of heterogeneity across observable characteristics, a major one being income [18].

Willingness-to-pay can be used to elicit valuations of any number of dimensions of treatments. One potential area pertinent to policy but relatively little used thus far is to aim directly at an individual's valuation of having access 
to treatment. A past idea is that one could try to elicit how much more of a premium they would pay if a particular new treatment was to be covered in their existing plan [19]. The idea here is that individuals assess the value or benefit of the particular treatment behind what amounts to a 'veil of ignorance,' knowing the effectiveness of the treatment, knowing the population prevalence of the illness, but not knowing whether they themselves will become ill with the condition for which the treatment is indicated [20,21]. One advantage is that people do make choices in the market in selecting a health plan based on premiums, but seldom directly purchase health technology, thus this stated preference exercise matches to some revealed preference behaviors in the market. Further, a more general rationale of using WTP is to understand the overall societal WTP for health that averages over all subgroups of abilities to pay in a society. This is in line with the provision of insurance where pooling of risk across individuals and over time is done to cater for people who develop health risks. It is also in line with the foundation of income distribution based on taxation. A perhaps more difficult consideration, though highly relevant, is to measure an individual's tradeoff between taxation and their value of providing access to treatments to other low-income or needy individuals. These are all potential areas for investment in future research.

In the midst of these difficulties in measuring value, a general societal goal would be to improve efforts at gathering and disseminating evidence regarding the impact of treatment on costs as well as on a wide variety of dimensions of health. For example, characterizing survival curves related to particular treatment choices and describing the frequency and severity of adverse outcomes associated with those particular treatments. Further, to improve the quality of information about treatment effects there could be more investment in mechanisms to generate and track pragmatic treatment 'trials' within large health systems [22]. Where comparison data are limited or unavailable, patients within a system could be randomized to receive one treatment or another and then tracked [23]. Moreover, there are ongoing efforts at better data collection via electronic health records, but there is much room for improvement in that area [24]. One fundamental improvement would be better coding and connections between prescriptions and their intended purpose. Currently, the diagnosis/intent of prescriptions is derived from linking International Classification of Diseases Ninth/Tenth Revision codes in office or hospitalization visits with prescriptions rather than directly in the prescription record and the coding itself is designed for billing rather than promoting clinical research most effectively. Additional efforts should be directed towards improving patient follow-up, delineating outcomes for those on their second line or more of therapy and those with co-morbid conditions, as well as assessing how behavior and other patient investments such as diet and exercise can interact with treatment choice.

Potential policy changes that could be considered include rules about making prices and costs explicit. In addition, there could be more investment in better measuring and describing the likelihood of having an illness and the subsequent impact of having access to a particular treatment, delineating expected copayments and deductibles to help with patient decision making. More effort could also be put into identifying and eliminating clearly inefficient and/or harmful incentives created by payment contracts such as higher profit margins for relatively undesirable drugs.

Given the complexities described above, including in particular heterogeneity in patient preferences, caution should be taken in rigidly promoting value-based coverage decisions and/or strictly value-based pricing [21]. There are also dynamic considerations of prices including a highly important and not well understood tradeoff between the expected profits from currently successful treatments and how that impacts current and future research and development expenditures and the subsequent odds of companies inventing impactful treatments in the future. However, whether it is quality-adjusted life-years or just simple lifeyears or other metrics, once there is evidence to establish a general WTP for marginal increases in these metrics, they can serve to improve value if used in promoting valuebased coverage decision and/or value-based pricing. Initial results from Yeung et al. evaluating value-based formulary design support this assertion [25]. This will only improve with better understanding of the marginal valuation of quality-adjusted life-years and/or life-years. Further, WTP exercise results can be easily used to value heterogeneity in outcomes provided such evidence is established.

Overall, there have been numerous efforts in the past to define, study, and improve understanding of the value of pharmaceuticals and to use this in price determination in USA. Hopefully, these efforts will result in a system that ensures fair profits to pharmaceutical manufacturers and innovators while being affordable to patients, payers, and society. Of note is a joint effort by the American Society of Health Economists and the International Society for Pharmacoeconomics and Outcomes Research to gather thought leaders and stakeholders to produce a paper of recommendations for moving the field forward and separately, the soon-to-be-released recommendations from the Second Panel on Cost Effectiveness in Health and Medicine [26, 27]. Without doubt, efforts to improve the balance of ensuring access, promoting investment, and reducing the costs of gathering and processing helpful information for treatment decisions will continue to be a highly valuable endeavor. 


\section{Compliance with Ethical Standards}

Funding None of the authors recieved any funding for this article

Conflict of interest None of the authors have any conflict of interest with the content of this commentary.

\section{References}

1. Tamori A, Enomoto M, Kawada N. Recent advances in antiviral therapy for chronic hepatitis C. Mediators Inflamm. 2016;2016:6841628.

2. Shrank WH, Barlow JF, Brennan TA. New therapies in the treatment of high cholesterol: an argument to return to goal-based lipid guidelines. JAMA. 2015;314(14):1443-4.

3. Dizon DS, Krilov L, Cohen E, et al. Clinical cancer advances 2016: annual report on progress against cancer from the American Society of Clinical Oncology. J Clin Oncol. 2016;34(9):987-1011.

4. Keehan SP, Cuckler GA, Sisko AM, et al. National health expenditure projections, 2014-24: spending growth faster than recent trends. Health Aff (Millwood). 2015;34(8):1407-17.

5. Schumock GT, Li EC, Suda KJ, et al. National trends in prescription drug expenditures and projections for 2015. Am J Health Syst Pharm. 2015;72(9):717-36.

6. Bach PB, Pearson SD. Payer and policy maker steps to support value-based pricing for drugs. JAMA. 2015;314(23):2503-4.

7. Jacobson M, Earle CC, Price M, et al. How Medicare's payment cuts for cancer chemotherapy drugs changed patterns of treatment. Health Aff (Millwood). 2010;29(7):1391-9.

8. Oliver MJ, Verrelli M, Zacharias JM, et al. Choosing peritoneal dialysis reduces the risk of invasive access interventions. Nephrol Dial Transplant. 2012;27(2):810-6.

9. Anderson JL, Heidenreich PA, Barnett PG, et al. ACC/AHA statement on cost/value methodology in clinical practice guidelines and performance measures: a report of the American College of Cardiology/American Heart Association Task Force on Performance Measures and Task Force on Practice Guidelines. J Am Coll Cardiol. 2014;63(21):2304-22.

10. Carlson RW, Jonasch E. NCCN evidence blocks. J Natl Compr Canc Netw. 2016;14(5 Suppl):616-9.

11. Schnipper LE, Davidson NE, Wollins DS, et al. American Society of Clinical Oncology statement: a conceptual framework to assess the value of cancer treatment options. J Clin Oncol. 2015;33(23):2563-77.
12. Neumann PJ, Cohen JT. Measuring the value of prescription drugs. N Engl J Med. 2015;373(27):2595-7.

13. Basu A, Jena AB, Goldman DP, et al. Heterogeneity in action: the role of passive personalization in comparative effectiveness research. Health Econ. 2014;23(3):359-73.

14. Lakdawalla DN, Romley JA, Sanchez Y, et al. How cancer patients value hope and the implications for cost-effectiveness assessments of high-cost cancer therapies. Health Aff (Millwood). 2012;31(4):676-82.

15. Gould SJ. The median isn't the message. Virtual Mentor. 2013;15(1):77-81.

16. Lynn J, McKethan A, Jha AK. Value-based payments require valuing what matters to patients. JAMA. 2015;314(14):1445-6.

17. Kirkdale R, Krell J, Brown CO, et al. The cost of a QALY. QJM. 2010;103(9):715-20.

18. Quevedo JFM, Hernandez IC, Espinosa JG, et al. The willingness-to-pay concept in question. Rev Saúde Pública. 2009;43(2):1-6.

19. Romley JA, Sanchez Y, Penrod JR, et al. Survey results show that adults are willing to pay higher insurance premiums for generous coverage of specialty drugs. Health Aff (Millwood). 2011;31(4):683-90.

20. Gafni A. Willingness-to-pay as a measure of benefits: relevant questions in the context of public decision making about health care programs. Med Care. 1991;29(12):1246-52.

21. Pauly MV. Valuing health care benefits in monetary terms. In: Sloan FA, editor. Valuing health care: costs, benefits, and effectiveness of pharmaceuticals and other medical technologies. New York: Cambridge University Press; 1995. p. 99-124.

22. Concannon TW, Guise JM, Dolor RJ, et al. A national strategy to develop pragmatic clinical trials infrastructure. Clin Transl Sci. 2014;7(2):164-71.

23. Basu A. Welfare implications of learning through solicitation versus diversification in health care. J Health Econ. 2015;42:165-73.

24. Menachemi N, Collum TH. Benefits and drawbacks of electronic health record systems. Risk Manag Health Policy. 2011;4:47-55.

25. Yeung K, Basu A, Hansen R, et al. Impact of a value-based formulary on medication utilization, health services utilization, and expenditures. Med Care. 2016. [Epub ahead of print].

26. Sanders G, Neumann P, Basu A, et al. Recommendations for conduct, methodological practices, and reporting of cost effectiveness analyses in health and medicine: Second Panel on Cost Effectiveness in Health and Medicine. JAMA. 2016;316(10):1093-103.

27. Neumann P, et al. Cost-effectiveness analysis in health and medicine. Cambridge: Oxford University Press; 2016. 